\title{
James Chen Annual Award for Best Journal Article
}

UMUAI is proud to announce that the following paper has been elected as the recipient of the 2020 James Chen Annual Award for Best Journal Article:

Effects of recommendations on the playlist creation behavior of users

Iman Kamahkhosh $^{1}$, Geoffray Bonnin ${ }^{2}$, Dietmar Jannach ${ }^{3}$

${ }^{1}$ E.ON Digital Technology GmbH, Essen, Germany

${ }^{2}$ Loria, Vandœuvre-lès-Nancy Cedex, France

${ }^{3}$ University of Klagenfurt, Klagenfurt am Wörthersee, Austria

UMUAI 30(1): 285-322

The paper was selected based on nominations from journal reviewers, editorial board members and guest editors, and a subsequent comparative review of the shortlisted papers by an award committee.

The James Chen Annual Award for Best Journal Article has been donated by the Chen family in commemoration of James R. Chen, a creative researcher in the area of user modeling and information retrieval, and twice a UMUAI author. The award carries a cash price of US\$ 1000.

Publisher's Note Springer Nature remains neutral with regard to jurisdictional claims in published maps and institutional affiliations. 